\title{
An agent-based model evaluation of economic control strategies for paratuberculosis in a dairy herd
}

\author{
Leslie J. Verteramo Chiu, ${ }^{* 1}$ Loren W. Tauer, $†$ Mohammad A. Al-Mamun, ${ }^{*}$ Karun Kaniyamattam, ${ }^{*}$ \\ Rebecca L. Smith, $\ddagger$ and Yrjo T. Grohn* \\ *Section of Epidemiology, College of Veterinary Medicine, and \\ †Charles H. Dyson School of Applied Economics and Management, College of Agriculture and Life Sciences, Cornell University, Ithaca, NY 14853 \\ ‡Department of Pathobiology, College of Veterinary Medicine, University of Illinois, Urbana 61802
}

\section{ABSTRACT}

This paper uses an agent-based simulation model to estimate the costs associated with Mycobacterium avium ssp. paratuberculosis (MAP), or Johne's disease, in a milking herd, and to determine the net benefits of implementing various control strategies. The net present value (NPV) of a 1,000-cow milking herd is calculated over $20 \mathrm{yr}$, parametrized to a representative US commercial herd. The revenues of the herd are generated from sales of milk and culled animals. The costs include all variable and fixed costs necessary to operate a representative 1,000-cow milking herd. We estimate the NPV of the herd with no MAP infection, under an expected endemic infection distribution with no controls, and under an expected endemic infection distribution with various controls. The initial number of cows in a herd with an endemic MAP infection is distributed as $75 \%$ susceptible, $13 \%$ latent, $9 \%$ low MAP shedding, and $3 \%$ high MAP shedding. Control strategies include testing using ELISA and fecal culture tests and culling of cows that test positive, and culling based on observable milk production decrease. Results show that culling cows based on test results does not increase the herd's NPV and in most cases decreases NPV due to test costs as well as false positives and negatives with their associated costs (e.g., culling healthy cows and keeping infected cows). Culling consistently low producing cows when MAP is believed to be present in the herd produces higher NPV over the strategy of testing and culling MAP infected animals, and over the case of no MAP control.

Key words: agent-based model, infection control strategy, Johne's disease paratuberculosis infection simulation, paratuberculosis economic cost

Received May 16, 2017.

Accepted March 12, 2018.

${ }^{1}$ Corresponding author: ljv9@cornell.edu

\section{INTRODUCTION}

Johne's disease is a chronic enteric disease in ruminants caused by the bacteria Mycobacterium avium ssp. paratuberculosis (MAP). Only adult animals show clinical symptoms of MAP infection, although infection can start in utero. Infected cows show progressive weight loss, periods of diarrhea, decreased milk production, lower reproductive rates, and are culled earlier, thereby affecting a dairy farm's profitability (Kennedy and Benedictus, 2001; Collins, 2003; Smith et al., 2009, 2010). The majority of dairy operations in the United States are believed to be infected with MAP (Lombard et al., 2013). It is estimated that MAP-associated costs to the milking industry in the United States are between $\$ 200$ and $\$ 250$ million per year (Ott et al., 1999), assuming a MAP prevalence of $22 \%$. It has been speculated that MAP may be a contributing factor to Crohn's disease in humans (Shulaw and Larey-Naugle, 2003; Naser et al., 2004), although the linkage is only for association and not causation.

Control strategies used to minimize the spread of MAP within a herd include testing and culling, improved hygiene (in facilities and animals), separate calves from dams at birth, use pasteurized milk to feed calves, and vaccination. Testing and culling is a widely studied strategy; however, there is the associated risk of culling false positives and keeping false negatives in the herd (Groenendaal et al., 2002; Cho et al., 2013; Smith, Al-Mamun, and Gröhn, 2017). Improved hygiene, including cattle management, may reduce transmission rates (Groenendaal and Galligan, 2003); however, the benefits of improved hygiene are not consistent. Some studies conclude that improved hygiene is no better than testing and culling (Smith et al., 2017), whereas others conclude that it is the most cost effective control for MAP (Groenendaal and Galligan, 2003). The benefits of vaccination have been difficult to estimate empirically because farms performing vaccination typically also improve their hygiene and management 
practices (Cho et al., 2012). Some studies conclude that even with a hypothetical high-efficacy vaccine, MAP may still be endemic in a herd due to vertical transmission (Lu et al., 2013).

Most of these previous studies used compartment models where movement of animals is modeled as a group rather than by individual animal. In compartment models, the herd is divided into homogeneous groups, or compartments, based on criteria such as age and infection status. The transition of animals between compartments is determined by differential or difference equations, often modeled as stochastic processes. Unlike agent-based models, compartment models cannot account for decisions made at the individual animal level. The advantage of an agent-based model is that it more closely mimics the actual individual animal decisions made on farms. Agent-based models provide full information of the agent, allowing more control on the data generated by each individual, and the possibility of specific controls based on each individual animal at any point in time based upon animal characteristics. Previous agent-based models focused on MAP transmission dynamics (Robins et al., 2015; Al-Mamun et al., 2016; Al-Mamun and Grohn, 2017); however, our focus is on including and estimating the economic costs of MAP and the benefits of some MAP control strategies in a commercial dairy herd.

Consequently, this paper analyzes the cost associated with MAP infection compared with a healthy herd using an agent-based simulation model. We test the hypothesis that the net present value (NPV) of a MAP infected herd can be improved by following various MAP control strategies, and whether MAP can be eradicated from the herd by applying those strategies. Because we compare the NPV of the herd among a set of control strategies, we may not be able to find the optimal control strategy among all possible strategies, but only among those analyzed. This is a limitation of this paper. The model and description of the population and infection processes are presented in the next section, then the control scenarios analyzed are described, followed by results and conclusion.

\section{MATERIALS AND METHODS}

The herd model is depicted in Figure 1, following Mitchell et al. (2008) and Smith et al. (2017). Population and infection dynamics parameters are described in Table 1 . The model is simulated daily for 20 years under different MAP control scenarios, and the NPV of the herd is estimated for the simulation period. The herd is initialized with 1,000 cows under a representative endemic infection distribution, and under a no infection case (see Table 2). The cows in the endemi-

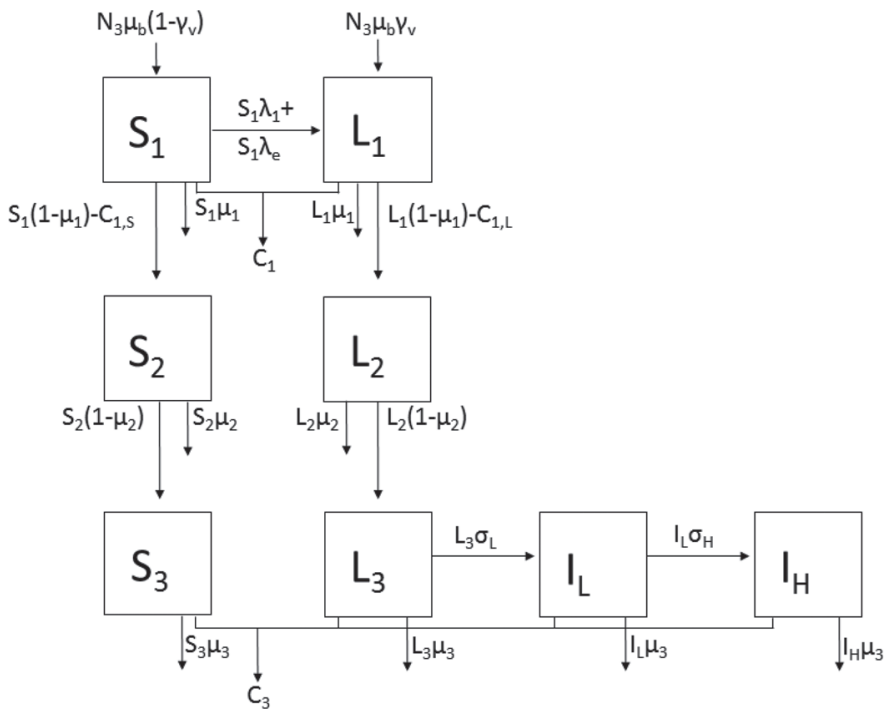

Figure 1. Animal dynamics across Mycobacterium avium ssp. paratuberculosis (MAP) infection status. There are 8 mutually exclusive animal compartments based on age and infection status: susceptible calves $\left(\mathrm{S}_{1}\right)$, latent calves $\left(\mathrm{L}_{1}\right)$, susceptible heifers $\left(\mathrm{S}_{2}\right)$, latent heifers $\left(\mathrm{L}_{2}\right)$, susceptible cows $\left(\mathrm{S}_{3}\right)$, latent cows $\left(\mathrm{L}_{3}\right)$, low MAP shedding cows $\left(\mathrm{I}_{\mathrm{L}}\right)$, and high MAP shedding cows $\left(\mathrm{I}_{\mathrm{H}}\right)$. Parameters are described in Table 2.

cally infected herd are distributed as follows: $75 \%$ are susceptible, $13 \%$ latent, 9\% low MAP shedding, and $3 \%$ high MAP shedding. The agent model was built in Matlab (MathWorks, Natick, MA).

\section{Population Dynamics}

The herd and each animal (agent) are divided into 3 age groups: calves, heifers, and cows. Calves are classified as animals from 0 to $60 \mathrm{~d}$ of age, heifers from 61 $\mathrm{d}$ of age until their first calving, and cows from first calving. When calves are born, they spend $1 \mathrm{~d}$ in the cow group in the presence of their dam. At the end of d 1, they are moved to the calf group. At $61 \mathrm{~d}$ of age, they are transferred to the heifer group. All heifers are transferred to the cow group once they give birth.

The 2 main processes in the population dynamics are pregnancy and culling. Pregnancy rates (conception rate $\times$ heat detection rate) were used for simplicity. The pregnancy rate of heifers is set at $18 \%$, whereas that of cows is set at $14 \%$. Once a heifer reaches $440 \mathrm{~d}$ of age it is inseminated. If the insemination is successful, the heifer will calve at $720 \mathrm{~d}$ of age (280-d pregnancy); otherwise, the heifer will be re-inseminated every $21 \mathrm{~d}$ until pregnant. Once a cow gives birth, a waiting period of $60 \mathrm{~d}$ occurs before insemination, continuing every 21 d until pregnant. All cows and heifers are culled if they do not become pregnant by the eighth insemination attempt. The cow will enter the milk production process 
Table 1. Infection and herd parameters and symbols used in the model

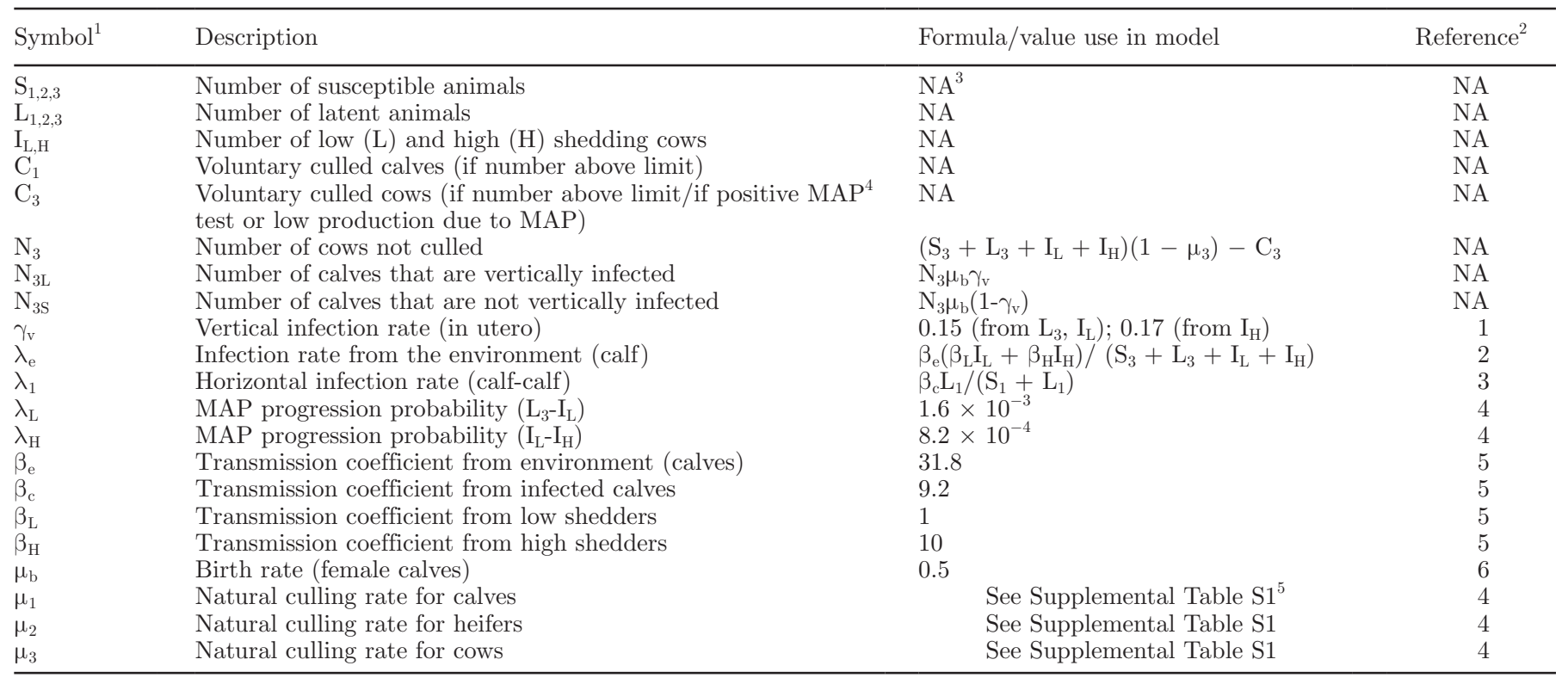

${ }^{1}$ Subscripts 1, 2, and 3 refer to calves, heifers, and cows, respectively. Reference values for $\lambda_{\mathrm{L}}$ and $\lambda_{\mathrm{H}}$ are $1.8 \times 10^{-3}$ and $9.0 \times 10^{-4}$, respectively. ${ }^{2}$ Daily values. References. 1: Sweeney et al. (1992); 2: van Schaik et al. (2003); 3: Smith et al. (2015); 4: Mitchell et al. (2008), values of reference in parentheses; 5 : estimated from the model; 6: assumed.

${ }^{3} \mathrm{NA}=$ not applicable.

${ }^{4} \mathrm{MAP}=$ Mycobacterium avium ssp. paratuberculosis.

${ }^{5}$ Supplemental Table S1 available at https://doi.org/10.3168/jds.2017-13175.

the day after giving birth, and will continue milking until $60 \mathrm{~d}$ before the next calving due date. The $60 \mathrm{~d}$ before calving is the dry period of the cow.

Every day each animal is subject to the natural culling process. The probability of culling depends on the age group of the animal and its parity. Culling occurs for 2 main reasons: involuntary culling that is outside of the farmer's control (accidents, sudden deaths) and voluntary culling based on the farmer's decision. The involuntary daily culling probabilities for calves and heifers are $2.43 \times 10^{-4}$ (annual rate of $0.0889 /$ calf) and $1.54 \times 10^{-5}$ (annual rate of $0.0056 /$ heifer), respectively, where yearly rates are converted to daily probabilities from the formula: probability $=1-\exp ^{(- \text {rate/365)}}$. The involuntary culling rates for calves and heifers were obtained from Mitchell et al. (2008), and reduced by 0.8 to produce stable simulations. Culling rates for cows were also based on Mitchell et al. (2008), and increase with the cow's parity. The involuntary culling rates and pregnancy rates are listed in Supplemental Table S1 (https://doi.org/10.3168/jds.2017-13175). Voluntary culling is based on reduced milk production, failure of successful insemination, and exceeding farm cow capacity. Additional voluntary culling beyond the baseline voluntary culling rate is modeled under the controls of testing and culling for MAP, or low milk production due to MAP.

Voluntary culling due to overpopulation occurs if the number of animals surpasses the limit of an animal classification group. The milking herd limit is set at 1,000 cows. The number of cows might exceed the farm capacity for cows when heifers are available for transfer to the cow group. When these excess heifers are available, all cows are ranked according to their expected milk production, and those with the lowest expected production are culled until the herd limit is reached again. As part of the management program to keep a stable number of replacement heifers, a limit in the

Table 2. Percent distribution of cow population by Mycobacterium avium ssp. paratuberculosis (MAP) infection level $^{1}$

\begin{tabular}{lcccc}
\hline MAP infection & Susceptible & Latent & Low shedding & High shedding \\
\hline No infection & 100 & 0 & 0 & 0 \\
MAP endemic infection & 75 & 13 & 9 & 3 \\
\hline
\end{tabular}

${ }^{1}$ Values as a percentage of the total cows in the herd. 
Table 3. Cost, revenue, and control parameter description

\begin{tabular}{lcl}
\hline Description & Formula/value & Source \\
\hline Test specificity, ELISA & 0.97 & Sweeney et al. (2014); Vitale et al. (2014) \\
Test specificity, FC & 1 & Sweeney et al. (2014); Vitale et al. (2014) \\
Test sensitivity for low shedders, ELISA & 0.24 & Sweeney et al. (2006); Clark et al. (2008) \\
Test sensitivity for low shedders, FC & 0.50 & Whitlock et al. (2000) \\
Test sensitivity for high shedders, ELISA & 0.78 & Sweeney et al. (2006); Clark et al. (2008) \\
Test sensitivity for high shedders, FC & 0.90 & Collins et al. (2006) \\
Cost per ELISA test $(\$)$ & 6 & Cornell University AHDC (2017) \\
Cost per FC test $(\$)$ & 36 & Cornell University AHDC (2017); Smith et al. (2017) \\
Days to get results after ELISA test & 0 & Smith et al. (2017) \\
Days to get results after FC test & 90,45 & Smith et al. (2017) \\
Number of days a cow's milk production is observed & 90,30 & Assumed \\
to decrease below normal before it is culled & & \\
Maximum number of cows allowed & 1,000 & Assumed \\
Maximum number of calves allowed & 83 & Estimated from model \\
Insemination cost, per event $(\$)$ & 20 & Kaniyamattam et al. (2016) \\
Pregnancy diagnosis cost, per event $(\$)$ & 8 & Kaniyamattam et al. (2016) \\
Milk price $(\$ / \mathrm{kg})$ & 0.427 & USDA NASS (2015) \\
Feed cost per kg of milk $(\$ / \mathrm{kg})$ & 0.286 & USDA ERS (2015) \\
Fixed costs per cow $(\$ / \mathrm{d})$ & 2.5 & Karszes (2014) \\
Discount rate, yearly & 0.05 & Assumed \\
Fixed cost of a newborn calf $(\$)$ & 150 & Karszes (2014) \\
Male calf sale price $(\$)$ & 150 & Karszes (2014) \\
Female calf sale price $(\$)$ & 250 & Karszes (2014) \\
Culled cow price $(\$)$ & 600 & USDA NASS (2017) \\
Culled price of a high shedder $(\$)$ & 540 & Smith et al. (2017) \\
\hline
\end{tabular}

${ }^{1} \mathrm{FC}=$ fecal culture.

number of calves at any time was also specified and set to 83. Any excess calves are culled based on age (youngest calves are culled first). The average parity in the modeled herd is 2.6 ( $38 \%$ culling rate).

\section{Infection Dynamics}

A flowchart of the model population and infection dynamics is shown in Figure 1, with parameter descriptions and values in Table 3 . The 3 age groups in Figure 1 (calves, heifers, and cows) are indicated by the subscripts 1, 2, and 3, respectively. Each group is further divided into 2 infection status levels for calves and heifers, and 4 infection status levels for cows. Calves and heifers can be susceptible (free of infection) or latent (sub-clinically). Cows have 2 additional infection status: low shedding and high shedding. Low shedding cows are defined as those cows that have MAP concentration of $<300 \mathrm{cfu} / \mathrm{g}$ of fecal culture tube. High shedding cows are defined as having $>300 \mathrm{cfu} / \mathrm{g}$ (Whitlock et al., 2000; van Schaik et al., 2005; van Roermund et al., 2007). Super shedders, animals that shed MAP pathogens in magnitudes of order many more times than a regular infected animal, contribute to a minor increase in the force of infection in a herd compared with regular infected animals (Mitchell et al., 2015), and thus are not separately modeled, although our overall infection rates reflect the presence of super shedders. Although, it has been suggested that adult animals can become infected with MAP, evidence indicates that if this infection occurs, it does not progress to clinical levels (Espejo et al., 2013; Mitchell et al., 2015) and is thus not modeled. Unlike low and high shedders, the MAP concentration of latent cows is undetectable. Susceptible, latent, low, and high shedders are denoted as $\mathrm{S}, \mathrm{L}, \mathrm{I}_{\mathrm{L}}$, and $\mathrm{I}_{\mathrm{H}}$, respectively.

Parameters, as well as variables and formulas estimated in the agent model, are listed in Table 2. The sequence of infection probability events is such that calves have a probability of being infected in utero, $\gamma_{\mathrm{v}}$, of $15 \%$ if the dam is a latent or low shedder, and $17 \%$ if the dam is a high shedder (Sweeney et al., 1992). Once the calf is born, it may become infected from the environment with probability $\lambda_{e}$, which captures the infection from the shared colostrum, and feces contact onto the calf. This infection rate depends on the proportion of low and high shedders in the cow group and accounts for the spread of contaminated feces and colostrum. It is assumed that calves spend $1 \mathrm{~d}$ exposed to environmental transmission. Calves are transferred to the calf group $24 \mathrm{~h}$ after birth, where they will remain until 60 d of age before being transferred to the heifer group at $61 \mathrm{~d}$ of age. Susceptible calves can become horizontally infected from latent calves, by the parameter $\lambda_{1}$, the probability of horizontal infection of calves in the calf group. The value of $\lambda_{1}$ depends on the number of latent calves, based on Smith et al. (2015). The values of $\sigma_{\mathrm{L}}$ and $\sigma_{\mathrm{H}}\left(1.8 \times 10^{-3}\right.$ and $9.04 \times 10^{-4}$, respectively $)$ as 


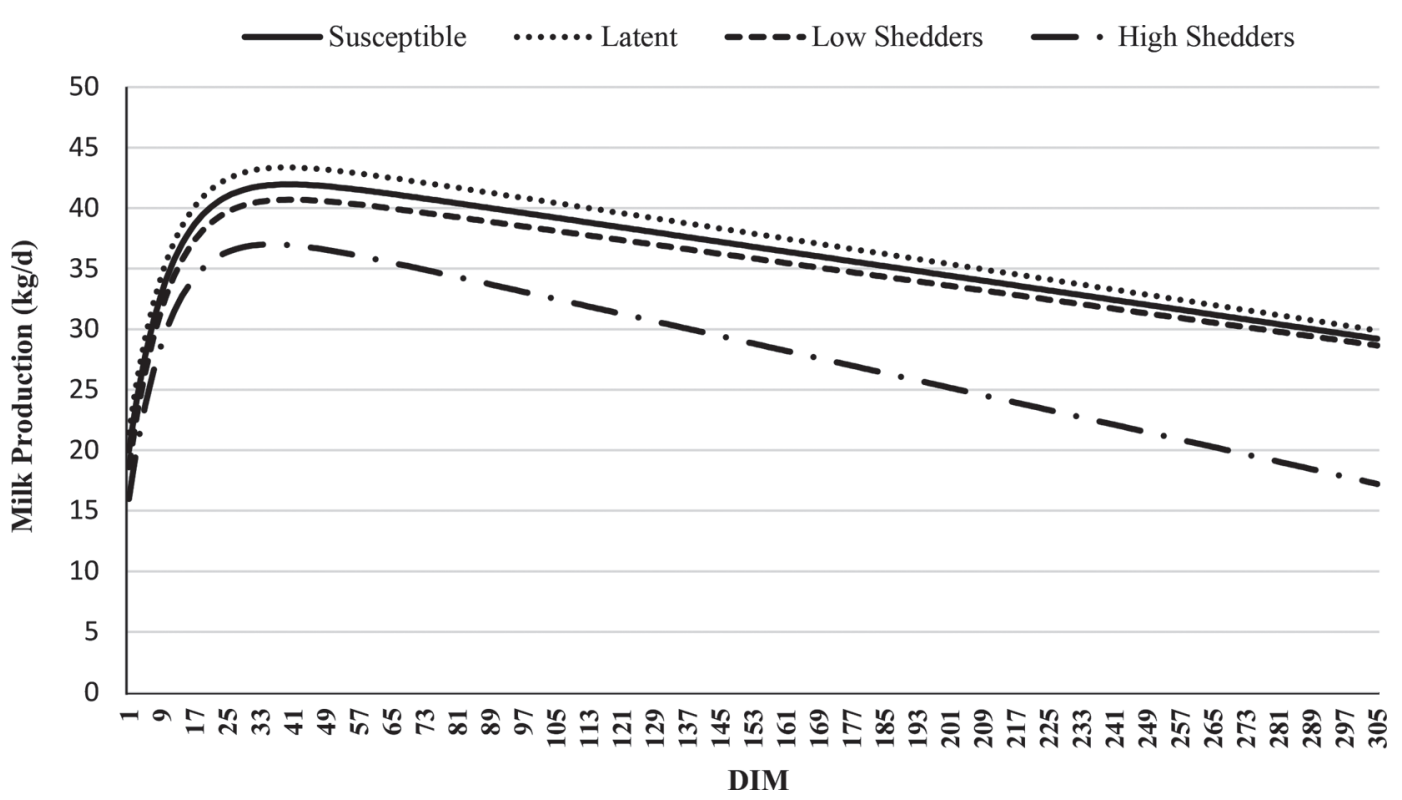

Figure 2. Milk production by Mycobacterium avium ssp. paratuberculosis infection status for second-parity cows. Cows are assumed to become infected at calving.

well as the formula for $\lambda_{\mathrm{e}}$ were based on van Schaik et al. (2003).

Infected calves transfer to infected heifers, who in turn become latent infected cows. Animals were modeled to acquire MAP immunity as they age. Susceptible but noninfected heifers and cows do not become infected at any time (Mitchell et al., 2008, 2012; Lu et al., 2010). Infected cows progress to a higher level of infection. The daily progression rate from latent to low shedders is $\sigma_{\mathrm{L}}$, and from low shedders to high shedders is $\sigma_{\mathrm{H}}$. High shedders, being the highest infection level, do not progress to another level.

The effect of MAP on milk production is considerable for high shedding cows, although low shedding cows also produce less milk on average than healthy cows. Figure 2 illustrates the effect of different levels of MAP infection on milk production. We follow a milk production function described in Smith et al. (2016). The milk production of susceptible, latent, and low shedders is very similar and was not considered a criterion for determining infection status. The average yearly milk production per cow in our model was set at $10,432 \mathrm{~kg}(23,000 \mathrm{lb})$, which is about the US average in 2016 (USDA NASS, 2017). The milk production loss of high shedders compared with noninfected cows with the same characteristics can reach $10 \%$ at early stages of lactation, but become $20 \%$ after $180 \mathrm{~d}$ into lactation, and up to $30 \%$ after $280 \mathrm{~d}$ into the lactation. When high shedders are in the herd and the number of cows exceeds farm capacity, due to replacement heifers enter- ing the cow compartment, the low production cows are culled only when they are more than 90 DIM.

\section{Costs, Revenues, and MAP Controls}

The variable costs associated with raising the animals in each age group as well as the revenues from milk sale and culling were computed daily. Fixed costs associated with each animal group were included in the total cost estimates. Cost and revenue parameters are shown in Table 3. The costs of raising a replacement heifer were obtained from Karszes (2014) and are used to model the daily costs from newborn to heifer. Feed cost and milk price were estimated as the US annual average from 2012 to 2016 and are obtained from the USDA's National Agricultural Statistics Service (USDA NASS, 2017). Feed cost is $\$ 0.286 / \mathrm{kg}$ of milk produced and represents the cost of a standardized feed ration required to produce a kilogram of milk. The milk price is set at $\$ 0.427 / \mathrm{kg}$. The difference between the price of a kilogram of milk and the feed cost to produce a kilogram of milk is called the milk margin and in our model is $\$ 0.140 / \mathrm{kg}$. Body weight and DMI for calves, heifers, and cows follows the estimations described in Nutrient Requirements of Dairy Cattle (NRC, 2001). These functions were estimated by Korver et al. (1985).

The NPV of the herd under the endemic infection distribution, and under no infection are first estimated. Then, the NPV of the endemic infected herd under different control strategies are estimated. These con- 
trol strategies are described in Table 4. The NPV of the herd is estimated by summing all cash flows, both positive (revenues) and negative (costs), in the herd per day, and then discounted to the initial year of the analysis. The positive cash flows consist of milk sales, and revenue from selling animals. Negative cash flows are all costs of raising heifers from birth feed cost, AI and veterinary costs, and a fixed cost per animal to account for the dairy operation costs, including labor and administration, and asset depreciation. The NPV in our model is estimated daily for $20 \mathrm{yr}$ with a terminal value at yr 21 . The terminal value is modeled as a perpetuity of the net cash flow occurring at yr 21 and is estimated by dividing the present value of the net cash that year by the discount rate. The NPV formula is

$$
\mathrm{NPV}=\sum_{t=1}^{20} \frac{\left(R_{t}-C_{t}\right)}{(1+r)^{t}}+\frac{\left(R_{\text {end }}-C_{\text {end }}\right)}{r(1+r)^{21}}
$$

where $R_{t}$ and $C_{t}$ are all revenues and costs, respectively, of the herd for year $t$. The variables $R_{\text {end }}$ and $C_{\text {end }}$ are the revenues and costs, respectively, at the end year of the NPV estimation (yr 21), which are assumed to continue into perpetuity. The parameter $r$ is the discount rate, set at 0.05 to reflect a risk free rate and a risk component. For simplicity, no inflationary component is built into the discount given that no costs and revenues increase over the 20 simulated years. It is also assumed that no increases in milk production occur from genetic improvement or technological change.

\section{Herd Scenarios and Control Strategies}

A description of the scenarios analyzed is listed in Table 4. Control strategy ELISA-fecal culture (FC) performs an ELISA test first, and then follows up with an FC test for all ELISA-positive cows the following day. The results of the FC test are obtained 90 d after the sample collection. Positive FC-tested cows are culled immediately to minimize MAP transmission in the herd. We also analyze the scenario where test-positive cows are culled once they enter their dry period, in the case they test MAP positive during lactation. Culling test-positive cows in their dry period may generate more cash flow as long as the test results are obtained when the cow is in lactation; however, this may come at the cost of having the MAP positive cow shedding MAP and potentially increasing the environmental transmission rate to calves. The ELISA test is performed once a year. The different ELISA-FC scenarios differ among each other on the starting parity of the cows tested.

In the control strategy cull low producers in Table 4, we assume the farmer understands that MAP may be a possibility (possibly due to an ELISA milk bulk tank test) and thus scrutinizes any consistent decrease in milk production by cow. Under scenario "cull low 90 DIM," if a cow's milk production drops below the expected production of a healthy cow's milk production for $90 \mathrm{~d}$, it will be culled on the following day. We also analyzed the scenario where the high shedder cows are identified as low producers when they are 30 DIM. Under the cull low producers scenarios, culling happens even if the number of cows falls below the herd size limit of 1,000 cows and no replacement heifer is available. In our model, all replacement heifers are raised on the farm and culled cows are not replaced with heifers from outside the farm. We also analyze the case where replacement heifers were introduced to the herd from outside farms if replacement heifers raised in the farm were not available in a short time. Replacement heifers from outside farms were priced at a $10 \%$ margin over the cost of producing heifers, reflecting a profit return

Table 4. Mycobacterium avium ssp. paratuberculosis (MAP) interventions ${ }^{1}$

\begin{tabular}{ll}
\hline Intervention name & Description \\
\hline Endemic infection & $\begin{array}{l}\text { Herd is endemically infected and no MAP intervention performed. } \\
\text { Testing and culling all parity } \geq 1 \text { cows once a year using ELISA and FC test. Test FC if ELISA positive. Cull } \\
\text { at } 90 \mathrm{~d} \text { after positive FC test. }\end{array}$ \\
ELISA-FC Par $\geq 2(90 \mathrm{~d})$ & $\begin{array}{l}\text { Testing and culling all parity } \geq 2 \text { cows once a year using ELISA and FC test. Test FC if ELISA positive. Cull } \\
\text { at } 90 \mathrm{~d} \text { after positive FC test. }\end{array}$ \\
ELISA-FC Par $\geq 3(90 \mathrm{~d})$ & $\begin{array}{l}\text { Testing and culling all parity } \geq 3 \text { cows once a year using ELISA and FC test. Test FC if ELISA positive. Cull } \\
\text { at } 90 \mathrm{~d} \text { after positive FC test. }\end{array}$ \\
ELISA-FC Par $\geq 4(90 \mathrm{~d})$ & $\begin{array}{l}\text { Testing and culling all parity } \geq 4 \text { cows once a year using ELISA and FC test. Test FC if ELISA positive. Cull } \\
\text { Observe and cull cows when production is consistently lower from that of a healthy cow for 90 DIM. Cull } \\
\text { immediately after 90 DIM. }\end{array}$ \\
Cull low 90 DIM & $\begin{array}{l}\text { Observe and cull cows when production is consistently lower from that of a healthy cow for } 30 \text { DIM. Cull } \\
\text { immediately after } 30 \text { DIM. }\end{array}$ \\
\hline
\end{tabular}

${ }^{1} \mathrm{~d}=$ fecal culture $(\mathrm{FC})$ test turnaround days. Par $=$ parity. 
to the supplier of heifers. We found that NPV is lower compared with raising all replacement heifers in the farm (results not shown).

\section{Model Simulation}

We began the simulation with the initialization of a 1,000-cow herd. The initial herd population was distributed in the following way: $45 \%$ of the cows were assigned in parity 1, 30\% in parity 2 , and $25 \%$ in parity 3. The initial cows had their age (d), pregnancy status, pregnancy days, and DIM randomly distributed according to parity. We allowed the simulation to run for $3,000 \mathrm{~d}$ to reach a stable population distribution of uninfected animals. Each scenario, including the endemic infection without controls, and a healthy herd, was simulated 100 times.

The next step was to incorporate MAP infection by allowing 100 heifers to be latently infected. After the introduction of the disease, a stable endemic MAP distribution of $75 \%$ uninfected cows, $13 \%$ latent, $9 \%$ low shedders, and $3 \%$ high shedders, was reached after $60 \mathrm{yr}$ of simulation, giving a MAP prevalence of about $20 \%$ and a shedding level of $12 \%$. These values are consistent with previous MAP models (Lu et al., 2010; Raizman et al., 2011; Mitchell et al., 2015; Beaver et al., 2017). The MAP shedding prevalence (low plus high shedders), ranging from 7 to $27 \%$ with a mean of $14 \%$, is found to be higher in larger dairy herds (Raizman et al., 2011). The stable endemic MAP herd was then used as a starting herd for the analysis of all scenarios. We incorporated various MAP control strategies to the endemic herd, ran the analysis for $20 \mathrm{yr}$, and estimated the NPV of each MAP control intervention, including a no intervention and a no infection case. For each of these control interventions some further modifications were modeled to determine whether these modifications produced significance changes in NPV and MAP prevalence. These included waiting to cull MAP-positive cows at the end of their lactation, decreasing FC test result turnover from 90 to $45 \mathrm{~d}$, allowing identical milk production for susceptible and latent cows, and culling the last calf of a MAP positive cow as well as the cow. We also tested the interventions under the following scenarios: a higher disease transmission rate, lower milk production, and both higher and lower milk income over feed cost. The results of these scenarios are presented below.

\section{RESULTS AND DISCUSSION}

The expected NPV of each intervention under the baseline scenario, with the associated cost of carrying out each control, are listed in Table 5. Control costs
Table 5. Net present value (NPV) by intervention and endemic infection state, assuming immediate culling of test-positive or lowproducing animals (baseline scenario) ${ }^{1}$

\begin{tabular}{|c|c|c|}
\hline Intervention & NPV & $\begin{array}{c}\text { Scenario expenses } \\
\text { in the NPV }\end{array}$ \\
\hline No infection & $\begin{array}{r}7,373,876 \\
(117,879)\end{array}$ & NA \\
\hline Endemic infection & $\begin{array}{r}6,957,891^{2} \\
(185,052)\end{array}$ & NA \\
\hline ELISA-FC Par $\geq 1(90 \mathrm{~d})$ & $\begin{array}{r}6,844,242^{3} \\
(177,407)\end{array}$ & $\begin{array}{r}109,377 \\
(1,811)\end{array}$ \\
\hline ELISA-FC Par $\geq 2(90 \mathrm{~d})$ & $\begin{array}{c}6,911,064^{2,3} \\
(143,089)\end{array}$ & $\begin{array}{l}73,502 \\
(1,246)\end{array}$ \\
\hline ELISA-FC Par $\geq 3(90 \mathrm{~d})$ & $\begin{array}{c}6,942,252 \\
(179,403)\end{array}$ & $\begin{array}{r}47,782 \\
\quad(985)\end{array}$ \\
\hline ELISA-FC Par $\geq 4(90 \mathrm{~d})$ & $\begin{array}{r}6,933,458 \\
(185,989)\end{array}$ & $\begin{array}{r}29,728 \\
(768)\end{array}$ \\
\hline Cull low 90 DIM & $\begin{array}{r}7,086,565^{3} \\
(138,279)\end{array}$ & NA \\
\hline Cull low 30 DIM & $\begin{array}{c}7,131,864^{2,3} \\
(166,650)\end{array}$ & NA \\
\hline
\end{tabular}

${ }^{1}$ Values in US dollars. Standard deviation in parentheses. $\mathrm{d}=$ fecal culture (FC) test turnaround days; NA = not applicable.

${ }^{2}$ Statistically different from the scenario above it in the table, only for endemic infection, test cull parity (Par) 2-4, and cull low 30 DIM. Statistical test at $95 \%$ confidence level.

${ }^{3}$ Statistically different from endemic infection. Statistical test at $95 \%$ confidence level.

are included in the NPV. The NPV of a herd with no MAP infection is estimated to be $\$ 7,373,876$. A herd in an endemic MAP infection state and under no MAP intervention has a lower estimated NPV of $\$ 6,957,891$, a difference of $\$ 415,985$ compared with the no infection case. This is equivalent to an annual cost per cow of $\$ 20.80$.

Previously estimates of annual MAP costs per cow in the United States were found to be between $\$ 22$ and $\$ 27$ (Ott et al., 1999).

Under all testing and culling interventions, the estimated NPV are no higher than that of the endemic infected herd with no implicit control strategy implemented. This suggests that an endemically infected herd should not engage in a testing and culling intervention. The costs of performing a testing and culling intervention does decrease, and in most cases the NPV increases, when testing begins in later parities. However, the NPV among the interventions of testing and culling starting in parity 2 , parity 3 , and parity 4 are not statistically different at the $95 \%$ confidence level. The NPV of testing and culling starting at parity 2 is statistically different (at 95\% confidence level) than that of testing starting at parity 1 . Testing and culling younger cows leads to unnecessary test costs and culling. Because few young cows have progressed to become low or high shedders, testing in early parities also increases the likelihood of culling healthy cows from false-positive test results. Thus, if a farm is considering 
a testing and culling intervention, it should test cows beginning in higher parities (parity 2 or higher).

The intervention of culling cows with fallen production, as an indicator of high MAP infection, is shown to be a better alternative than the testing and culling interventions, even when the number of cows in the herd may fall below the herd capacity of 1,000 cows and no replacement heifer may be readily available. This intervention assumes that farmers know that their herd is MAP infected and they pay more attention and take action to a persistent decrease in milk production compared with a healthy cow. This would signal to the farmer that the cow may be MAP infected, and thus, culling is warranted. Of course, decreased production may be due to reasons other than MAP, but those reasons may also warrant culling. We assume that no extra costs are associated with the cull low producers intervention because it only relies on measurement or observation and experience. The degree to which farmers can effectively detect a MAP-infected cow through observation of decreased milk production would depend on the experience and accurate production measurement capacity on the farm. We tested 2 of these interventions, assuming the farmer can detect low milk producers if they have been high shedders for at least 90 or 30 DIM, reflecting differences in monitoring milk yield. The NPV of each of the 2 interventions (high shedders with 90 and 30 DIM) are $\$ 7,086,565$ and $\$ 7,131,864$, respectively. The NPV of each of the cull low producers interventions are statistically different $(P<0.05)$ from the NPV of every testing and culling intervention.

The MAP interventions help minimize the prevalence of MAP in the herd, especially when positive animals are culled as soon as they are MAP detected. Culling as early as possible, however, may reduce milk revenue if the cow is detected while lactating. We tested the hypothesis that culling MAP-positive animals immediately or at the end of lactation results in similar NPV for all control scenarios. Results are shown in Table 6 . We found that for almost all interventions, culling at the end of lactation does not produce a statistically different NPV than culling immediately after MAP detection. Only the intervention of culling diminishing milk producers in 90 DIM produces a higher NPV at a $95 \%$ confidence level. Waiting to cull until the dry period when decreased production cows are detected 90 DIM, results in an increase in NPV of $\$ 78,824$ over culling immediately.

Our milk production function models the production of latent cows higher than that of susceptible cows (Smith et al., 2016). The reason for this observed increase in milk production for latent cows is not well understood but may cause these cows to remain in the herd if the value of this incremental milk is greater than the externality cost of infecting calves. To determine the effect of the assumption of latent cows producing more milk than susceptible (noninfected) cows, we estimate the NPV of all interventions assuming that the milk production of latent and susceptible cows are equal. Results are shown in Table 7. Keeping milk production the same for latent and susceptible cows has a negative, albeit small and mostly not statistically significant, effect on expected NPV. This negative effect ranges from one to $0.1 \%$ depending on the intervention. However, only for the intervention of culling reduced milk producers in 30 DIM is the NPV difference from the 2 milk production assumptions statistically significant at 95\% confidence level. Culling reduced milk producers in 30 DIM when latent and susceptible cows are assumed to produce the same amount of milk results in a NPV of $\$ 47,925$ less than under the assumption that latent cows produce more milk than susceptible cows (a difference in NPV of $0.7 \%$ ).

To analyze the benefits of an improved FC test turnaround time, we estimated the NPV of the testing and culling interventions when the time to obtain the FC results is reduced from $90 \mathrm{~d}$ to $45 \mathrm{~d}$ under immediate culling (baseline scenario). The differences in NPV of each of the testing and culling interventions under a 90and $45-\mathrm{d}$ FC test turnaround time are not statistically different from each other at a 95\% confidence level. That is, an FC test result turnaround time of $45 \mathrm{~d}$ does not improve NPV compared with a 90-d turnaround time. Results are shown in Supplemental Table S2 (https://doi.org/10.3168/jds.2017-13175).

Calves born from infected cows have a higher probability of becoming MAP infected. We tested whether

Table 6. Net present value (NPV) by intervention, assuming culling of test-positive or low-producing animals when not lactating ${ }^{1}$

\begin{tabular}{lcc}
\hline Intervention & NPV & $\begin{array}{c}\text { Scenario expenses } \\
\text { in the NPV }\end{array}$ \\
\hline ELISA-FC Par $\geq 1(90 \mathrm{~d})$ & $6,875,409^{2}$ & 109,827 \\
& $(174,152)$ & $(1,736)$ \\
ELISA-FC Par $\geq 2(90 \mathrm{~d})$ & $6,916,327$ & $(1,683$ \\
& $(160,241)$ & $(1,299)$ \\
ELISA-FC Par $\geq 3(90 \mathrm{~d})$ & $6,935,940$ & $(1,012)$ \\
ELISA-FC Par $\geq 4(90 \mathrm{~d})$ & $(180,064)$ & 29,747 \\
Cull low 90 DIM & $(200,6960)$ & NA \\
Cull low 30 DIM & $7,165,389^{2,3}$ & \\
& $(145,179)$ & $\mathrm{NA}$ \\
\hline
\end{tabular}

${ }^{1}$ Values in US dollars. Standard deviation in parentheses. Scenario expenses are included in NPV. $\mathrm{d}=$ fecal culture $(\mathrm{FC})$ test turnaround days; NA = not applicable; Par = parity.

${ }^{2}$ Statistically different from endemic infection (from Table 5). Statistical test at $95 \%$ confidence level.

${ }^{3}$ Statistically different from the corresponding scenario under culling immediately (from Table 5). Statistical test at $95 \%$ confidence level. 
Table 7. Net present value (NPV) by intervention under equivalent milk production in latent and susceptible cows, assuming immediate culling of test-positive or low-producing animals ${ }^{1}$

\begin{tabular}{lcc} 
Intervention & NPV & $\begin{array}{c}\text { Scenario expenses } \\
\text { in the NPV }\end{array}$ \\
\hline Endemic infection & $6,883,072^{2,3}$ & $\mathrm{NA}$ \\
ELISA-FC Par $\geq 1(90 \mathrm{~d})$ & $6,789,464^{3,4}$ & 109,521 \\
& $(169,996)$ & $(1,662)$ \\
ELISA-FC Par $\geq 2(90 \mathrm{~d})$ & $6,853,695^{2,3}$ & 73,355 \\
& $(159,078)$ & $(1,308)$ \\
ELISA-FC Par $\geq 3(90 \mathrm{~d})$ & $6,873,428^{3}$ & 47,988 \\
& $(187,419)$ & $(947)$ \\
ELISA-FC Par $\geq 4(90 \mathrm{~d})$ & $6,883,988$ & 29,721 \\
& $(191,183)$ & $(888)$ \\
Cull low 90 DIM & $7,077,219^{4}$ & $\mathrm{NA}$ \\
Cull low 30 DIM & $(160,080)$ & $\mathrm{NA}$ \\
& $7,083,938^{3,4}$ & \\
\hline
\end{tabular}

${ }^{1}$ Values in US dollars. Standard deviation in parentheses. Scenario expenses are included in NPV. $d=$ fecal culture (FC) test turnaround days; $\mathrm{NA}=$ not applicable.

${ }^{2}$ Statistically different from the scenario above it in the table, only for endemic infection (compared with no infection in Table 5), test cull parity (Par) 2-4, and cull low 30 DIM. Endemic infection is tested against no infection from Table 5. Statistical test at $95 \%$ confidence level.

${ }^{3}$ Statistically different from the corresponding scenario from Table 5. Statistical test at $95 \%$ confidence level.

${ }^{4}$ Statistically different from endemic infection. Statistical test at $95 \%$ confidence level.

eliminating high-risk calves at birth decreases MAP prevalence in the herd. Under this scenario, testpositive cows or cows that have low milk production possibly due to MAP are culled immediately as well as their last calf. The NPV of the testing and culling interventions under this scenario of culling the last calf from test-positive or reduced production cows are not statistically different (at 95\% confidence level) from the scenario of not culling the last calf. Results are shown in Table 8. The NPV of the interventions of culling reduced milk producers (for both 90 and 30 DIM), as well as culling their last calf, result in lower NPV compared with the baseline scenario (Table 5). Culling reduced milk producers in 90 and 30 DIM results in $\$ 68,797$ and $\$ 87,772$ lower NPV, respectively, compared with not culling the last calf (these differences are statistically significant at $95 \%$ confidence level). The intervention of also culling the last calf of a MAP-positive or reduced production cow does not improve the NPV of the herd.

None of the interventions modeled is sufficient to eradicate MAP from the herd. Table 9 shows the percentage of MAP shedders in the cow group at the end of $20 \mathrm{yr}$ of simulation for all scenarios analyzed, which may affect MAP prevalence. The numbers of infected cows by MAP status for each intervention and scenario analyzed are shown in Supplemental Table S3 (https:// doi.org/10.3168/jds.2017-13175).

In Table 9 we can see that the average percentage of MAP-shedding cows in the cow population under endemic infection state without intervention is $12 \%$. This is the sum of low and high shedders as a percentage of total number of cows. Doing any type of intervention decreases the percentage of MAP shedders in the cow population. For instance, under the baseline scenario, applying the intervention testing and culling parity 1 decreases MAP shedding prevalence by $75 \%$. Among the scenarios analyzed, decreasing FC test turnover to $45 \mathrm{~d}$ generates the largest reduction in MAP shedding prevalence with respect to the baseline scenario. The decrease in MAP shedding prevalence ranges from 20 to $3 \%$. For the interventions of culling reduced milk producers, the scenario of "culling last calf" produced the largest decrease in MAP shedding with respect to the baseline scenario, 10 and $13 \%$ for "cull low 90 DIM" and "cull low 30 DIM," respectively.

We tested the sensitivity of our results from the baseline scenario by estimating the NPV of an infected herd under the following changes: MAP transmission rate increase by $20 \%$, decrease in milk production by $20 \%$, milk income over feed costs set as the lowest and highest annual US national average of the 5-yr period during 2012 to 2016 . The high value of the milk income over feed costs is $\$ 0.239 / \mathrm{kg}$ of milk, whereas the low

Table 8. Net present value (NPV) by intervention assuming immediate culling of test-positive or low-producing animals and their last calf ${ }^{1}$

\begin{tabular}{lcc}
\hline Intervention & $\mathrm{NPV}$ & $\begin{array}{c}\text { Scenario expenses } \\
\text { in the NPV }\end{array}$ \\
\hline ELISA-FC Par $\geq 1(90 \mathrm{~d})$ & $6,804,050^{2}$ & 109,482 \\
& $(189,032)$ & $(1,677)$ \\
ELISA-FC Par $\geq 2(90 \mathrm{~d})$ & $6,928,022^{3}$ & 73,108 \\
& $(165,256)$ & $(1,278)$ \\
ELISA-FC Par $\geq 3(90 \mathrm{~d})$ & $6,899,467^{2}$ & 47,855 \\
& $(180,141)$ & $(1,054)$ \\
ELISA-FC Par $\geq 4(90 \mathrm{~d})$ & $6,927,703$ & 29,719 \\
Cull low 90 DIM & $(173,721)$ & $(903)$ \\
& $7,017,768^{2,4}$ & $\mathrm{NA}$ \\
Cull low 30 DIM & $(172,637)$ & $\mathrm{NA}$ \\
& $7,044,092^{2,4}$ & \\
\hline
\end{tabular}

${ }^{1}$ Values in US dollars. Standard deviation in parentheses. Scenario expenses are included in NPV. $\mathrm{d}=$ fecal culture $(\mathrm{FC})$ test turnaround days; $\mathrm{NA}=$ not applicable.

${ }^{2}$ Statistically different from endemic infection (from Table 5). Statistical test at $95 \%$ confidence level.

${ }^{3}$ Statistically different from the scenario above it in the table, only for test cull parity (Par) 2-4 and cull low 30 DIM. Endemic infection is tested against no infection from Table 5. Statistical test at $95 \%$ confidence level.

${ }^{4}$ Statistically different than the corresponding scenario from Table 5 . Statistical test at $95 \%$ confidence level. 
value is $\$ 0.094 / \mathrm{kg}$ of milk. Results of the sensitivity analysis are shown in Supplemental Tables S4 through S7 (https://doi.org/10.3168/jds.2017-13175).

The results of the interventions under the assumption of decreasing milk production by $20 \%$ (Table 4 in the Supplemental), and increasing MAP transmission rate by 20\% (Supplemental Table S5; https://doi.org/ $10.3168 /$ jds.2017-13175) are qualitatively similar to the baseline scenario (Table 5). For the low and high milk margin scenarios, however, there is a difference in the ranking of the interventions by NPV. For the low milk margin case (Supplemental Table S6; https://doi.org/ 10.3168/jds.2017-13175), the NPV of all interventions are negative. Practically all interventions produce a higher NPV than the endemic case. The intervention ELISA-FC parity 1 is not statistically different (at $95 \%$ confidence level) from the endemic case, and the rest of the interventions are statistically different from the endemic infection case at a $95 \%$ confidence level. One reason the interventions produce a higher NPV than the endemic infection case under no interventions is that with a low milk margin over feed costs, the price of milk relative to the price of carcass value (revenue from culling cows) is lower, and selling culled animals for meat becomes more profitable relative to selling milk. Under the low milk margin scenario, the NPV difference between a healthy herd and an endemically infected herd with MAP is $\$ 250,749$, which is equivalent to an annual MAP cost per cow of $\$ 12.54$.

The NPV results when the milk margin is set at the highest annual value from the period 2012 to 2016 are shown in Supplemental Table S7 (https://doi.org/ 10.3168/jds.2017-13175). In this scenario, all testing and culling interventions have a lower NPV than the endemic infection case, similar to the baseline case in Table 5, and the interventions "cull low 90 DIM" and "cull low 30 DIM" have a higher NPV than the testing and culling interventions, yet only "cull low 90 DIM" has a NPV higher than the endemic infection case. However, neither of the cull low interventions is statistically different from the endemic infection case (at 95\% confidence level). The NPV of all the testing and culling interventions are statistically different from the NPV of the endemic infection case at $95 \%$ confidence level. The NPV of the testing and culling interventions are not statistically different from each other, and the NPV of the "cull low 90 DIM" and "cull low 30 DIM" interventions are also not statistically different (at 95\% confidence level). The NPV difference between a healthy herd and the endemic infected case under a high milk margin is $\$ 801,076$, or an annual cost per cow of $\$ 40.05$.

\section{CONCLUSIONS}

This paper estimated the NPV of a 1,000-cow dairy herd endemically infected with MAP and implementing various MAP interventions. We also estimated the NPV of a healthy herd. We applied 2 general interventions: testing and culling, modeled as following up all ELISA-positive test cows with an FC test, and culling FC-positive cows, implemented for various cow parities, and culling high-MAP-shedding cows identified by daily milk production becoming consistently lower than that of a corresponding non-high-shedding cow. Our results show that the ELISA-FC test strategy, where all cows are first tested using the ELISA test and if positive followed up with a FC test, generates a lower NPV than no controls in a MAP-infected herd. This implies that the testing and culling strategy employing the ELISA test as a pre-filter for the FC test would not be recommended given the parameters of our model.

Table 9. Mycobacterium avium ssp. paratuberculosis (MAP) shedders (low and high shedders) as percentage of total number of cows by intervention and scenario ${ }^{1}$

\begin{tabular}{lcccc}
\hline & \multicolumn{3}{c}{ Scenario } \\
\cline { 2 - 5 } Intervention & Baseline & Cull end of lactation & Cull last calf & FC test turnover $45 \mathrm{~d}$ \\
\hline ELISA-FC Par $\geq 1(90 \mathrm{~d})$ & 3.12 & 3.55 & 3.25 & 2.86 \\
ELISA-FC Par $\geq 2(90 \mathrm{~d})$ & 3.87 & 4.43 & 3.76 & 3.10 \\
ELISA-FC Par $\geq 3(90 \mathrm{~d})$ & 5.70 & 6.67 & 5.96 & 5.44 \\
ELISA-FC Par $\geq 4(90 \mathrm{~d})$ & 8.04 & 8.63 & 8.55 & 7.78 \\
Cull low 90 DIM & 2.14 & 2.05 & 1.93 & $\mathrm{NA}$ \\
Cull low 30 DIM & 1.44 & 1.69 & 1.24 & $\mathrm{NA}$ \\
& & & \\
$\begin{array}{l}1 \\
\mathrm{~d}=\text { fecal culture (FC) test turnaround days; Par }=\text { parity; NA }=\text { not applicable. Endemic infection MAP }\end{array}$
\end{tabular}


In contrast, a strategy of culling cows with falling milk production, which may be an indication of MAP infection in a suspected herd, provides a higher NPV than the no control case (although the difference is statistically not significant). Our results are consistent with empirical and anecdotal evidence found on US dairy farms. Many farmers with infected herds appear not to engage in costly MAP control strategies; instead, they carry out business as usual. The result by default is economic control of MAP in their herds although not MAP elimination. Our results do not undermine good management practices, including herd and facilities hygiene, in MAP control. Our model estimates the annual cost per cow in an endemically infected herd to be $\$ 20.80$.

\section{ACKNOWLEDGMENTS}

This work was funded by USDA-National Institute of Food and Agriculture and Food Research Initiative (AFRI) grant \#2014-67015-2240 as part of the joint USDA-National Science Foundation (NSF)-National Institutes of Health (NIH)-United Kingdom Biotechnology and Biological Sciences Research Council (BBSRC)-Binational Science Foundation (BSF) Ecology and Evolution of Infectious Diseases program.

\section{REFERENCES}

Al-Mamun, M. A., and Y. T. Grohn. 2017. A Multiscale Agent-Based Simulation of a Dairy Herd. Spring Simulation Multi-Conference, Apr 23-26, Virginia Beach, VA. Society for Computer Simulation International, San Diego, CA.

Al-Mamun, M. A., R. L. Smith, Y. H. Schukken, and Y. T. Grohn. 2016. Modeling of Mycobacterium avium ssp. paratuberculosis dynamics in a dairy herd: An individual based approach. J. Theor. Biol. 408:105-117. https://doi.org/10.1016/j.jtbi.2016.08.014.

Beaver, A., R. W. Sweeney, E. Hovingh, D. R. Wolfgang, Y. T. Gröhn, and Y. H. Schukken. 2017. Longitudinal relationship between fecal culture, fecal quantitative PCR, and milk ELISA in Mycobacterium avium ssp. paratuberculosis-infected cows from low-prevalence dairy herds. J. Dairy Sci. 100:7507-7521.

Cho, J., L. W. Tauer, Y. H. Schukken, M. I. Gómez, R. L. Smith, Z. Lu, and Y. T. Grohn. 2012. Economic analysis of Mycobacterium avium subspecies paratuberculosis vaccines in dairy herds. J. Dairy Sci. 95:1855-1872. https://doi.org/10.3168/jds.2011-4787.

Cho, J., L. W. Tauer, Y. H. Schukken, R. L. Smith, Z. Lu, and Y. T. Grohn. 2013. Cost-effective control strategies for Johne's disease in dairy herds. Can. J. Ag. Econ./Rev. Can. D'ag., 61:583-608. https://doi.org/10.1111/j.1744-7976.2012.01270.x.

Clark, D. L., J. J. Koziczkowski, R. P. Radcliff, R. A. Carlson, and J. L. E. Ellingson. 2008. Detection of Mycobacterium avium subspecies paratuberculosis: Comparing fecal culture versus serum enzyme-linked immunosorbent assay and direct fecal polymerase chain reaction. J. Dairy Sci. 91:2620-2627. https://doi.org/10 .3168/jds.2007-0902.

Collins, M. 2003. Paratuberculosis: Review of present knowledge. Acta Vet. Scand. Accessed Feb. 11, 2017. http://www.johnes.org/ handouts/files/CollinsMT-ReviewActaVetScand03.pdf.

Collins, M. T., I. A. Gardner, F. B. Garry, A. J. Roussel, and S. J. Wells. 2006. Consensus recommendations on diagnostic testing for the detection of paratuberculosis in cattle in the United States. J. Am. Vet. Med. Assoc. 229:1912-1919. https://doi.org/10.2460/ javma.229.12.1912.

Cornell University AHDC (Animal Health Diagnostic Center). 2017. Animal Health Diagnostic Center. Accessed Feb. 4, 2017. https:// ahdc.vet.cornell.edu/.

Espejo, L. A., N. Kubat, S. M. Godden, and S. J. Wells. 2013. Effect of delayed exposure of cattle to Mycobacterium avium subsp paratuberculosis on the development of subclinical and clinical Johne's disease. Am. J. Vet. Res. 74:1304-1310. https://doi.org/10.2460/ ajvr.74.10.1304.

Groenendaal, H., and D. T. Galligan. 2003. Economic consequences of control programs for paratuberculosis in midsize dairy farms in the United States. J. Am. Vet. Med. Assoc. 223:1757-1763. https:// doi.org/10.2460/javma.2003.223.1757.

Groenendaal, H., M. Nielen, A. W. Jalvingh, S. H. Horst, D. T. Galligan, and J. W. Hesselink. 2002. A simulation of Johne's disease control. Prev. Vet. Med. 54:225-245. https://doi.org/10.1016/ S0167-5877(02)00027-2.

Kaniyamattam, K., M. A. Elzo, J. B. Cole, and A. De Vries. 2016. Stochastic dynamic simulation modeling including multitrait genetics to estimate genetic, technical, and financial consequences of dairy farm reproduction and selection strategies. J. Dairy Sci. 99:8187-8202. https://doi.org/10.3168/jds.2016-11136.

Karszes, J. 2014. Dairy Replacement Programs: Costs \& Analysis 3rd Quarter 2012. Extension Bulletin 2014-02, Department of Animal Science and Charles H. Dyson School of Applied Economics and Management, Cornell University, Ithaca, NY.

Kennedy, D., and G. Benedictus. 2001. Control of Mycobacterium avium ssp. paratuberculosis infection in agricultural species. Revue Scientifique et Technique Accessed Feb. 11, 2017. https://www.researchgate.net/profile/Geart_Benedictus/ publication/12044464_Control_of_Mycobacterium_avium _subs_paratuberculosis_infection_in_agricultural_species/links/ 5660842808ae418a786664bf.pdf.

Korver, S., J. M. van Arendonk, and W. J. Koops. 1985. A function for live-weight change between two calvings in dairy cattle. Anim. Prod. 40:233-241. https://doi.org/10.1017/S0003356100025332.

Lombard, J. E., I. A. Gardner, S. R. Jafarzadeh, C. P. Fossler, B. Harris, R. T. Capsel, and W. O. Johnson. 2013. Herd-level prevalence of Mycobacterium avium ssp. paratuberculosis infection in United States dairy herds in 2007. Prev. Vet. Med. 108:234-238. https:// doi.org/10.1016/j.prevetmed.2012.08.006.

Lu, Z., Y. H. Schukken, R. L. Smith, and Y. T. Grohn. 2010. Stochastic simulations of a multi-group compartmental model for Johne's disease on US dairy herds with test-based culling intervention. J. Theor. Biol. 264:1190-1201. https://doi.org/10.1016/j.jtbi.2010.03 .034 .

Lu, Z., Y. H. Schukken, R. L. Smith, and Y. T. Gröhn. 2013. Using vaccination to prevent the invasion of Mycobacterium avium subsp. paratuberculosis in dairy herds: A stochastic simulation study. Prev. Vet. Med. 110:335-345.

Mitchell, R. M., G. F. Medley, M. T. Collins, and Y. H. Schukken. 2012. A meta-analysis of the effect of dose and age at exposure on shedding of Mycobacterium avium subspecies paratuberculosis (MAP) in experimentally infected calves and cows. Epidemiol. Infect. 140. https://doi.org/10.1017/S0950268811000689.

Mitchell, R. M., R. H. Whitlock, Y. T. Gröhn, and Y. H. Schukken. 2015. Back to the real world: Connecting models with data. Prev. Vet. Med. 118:215-225. https://doi.org/10.1016/j.prevetmed.2014 .12.009.

Mitchell, R. M., R. H. Whitlock, S. M. Stehman, A. Benedictus, P. P. Chapagain, Y. T. Grohn, and Y. H. Schukken. 2008. Simulation modeling to evaluate the persistence of Mycobacterium avium ssp. paratuberculosis (MAP) on commercial dairy farms in the United States. Prev. Vet. Med. 83:360-380. https://doi.org/10.1016/j .prevetmed.2007.09.006.

Naser, S. A., G. Ghobrial, C. Romero, and J. F. Valentine. 2004 Culture of Mycobacterium avium subspecies paratuberculosis from the blood of patients with Crohn's disease. Lancet 364:1039-1044. 
NRC. 2001. Nutrient Requirements of Dairy Cattle. 7th rev. ed. National Academies Press, Washington, DC. https://doi.org/10 $.17226 / 9825$

Ott, S. L., S. J. Wells, and B. A. Wagner. 1999. Herd-level economic losses associated with Johne's disease on US dairy operations. Prev. Vet. Med. 40:179-192. https://doi.org/10.1016/S0167 $-5877(99) 00037-9$

Raizman, E. A., S. J. Wells, C. A. Muñoz-Zanzi, and S. Tavornpanich. 2011. Estimated within-herd prevalence (WHP) of Mycobacterium avium ssp. paratuberculosis in a sample of Minnesota dairy herds using bacterial culture of pooled fecal samples. Can. J. Vet. Res. $75: 112-116$.

Robins, J., S. Bogen, A. Francis, A. Westhoek, A. Kanarek, S. Lenhart, and S. Eda. 2015. Agent-based model for Johne's disease dynamics in a dairy herd. Vet. Res. 46:68. https://doi.org/10.1186/ s13567-015-0195-y.

Shulaw, W. P., and A. Larey-Naugle. 2003. Paratuberculosis: A food safety concern? Pages 351-358 in Microbial Food Safety in Animal Agriculture. M. E. Torrence and R. E. Isaacson, ed. Iowa State Press, Ames.

Smith, R. L., M. A. Al-Mamun, and Y. T. Gröhn. 2017. Economic consequences of paratuberculosis control in dairy cattle: A stochastic modeling study. Prev. Vet. Med. 138:17-27. https://doi.org/10 $.1016 /$ j.prevetmed.2017.01.007.

Smith, R. L., Y. T. Gröhn, A. K. Pradhan, R. H. Whitlock, J. S. Van Kessel, J. M. Smith, D. R. Wolfgang, and Y. H. Schukken. 2016. The effects of progressing and nonprogressing Mycobacterium avium ssp. paratuberculosis infection on milk production in dairy cows. J. Dairy Sci. 99:1383-1390. https://doi.org/10.3168/ jds.2015-9822.

Smith, R. L., Y. T. Grohn, A. K. Pradhan, R. H. Whitlock, J. S. Van Kessel, J. M. Smith, D. R. Wolfgang, and Y. H. Schukken. 2009. A longitudinal study on the impact of Johne's disease status on milk production in individual cows. J. Dairy Sci. 92:2653-2661. https:// doi.org/10.3168/jds.2008-1832.

Smith, R. L., Y. H. Schukken, and Y. T. Gröhn. 2015. A new compartmental model of Mycobacterium avium ssp. paratuberculosis infection dynamics in cattle. Prev. Vet. Med. 122:298-305. https:// doi.org/10.1016/j.prevetmed.2015.10.008.

Smith, R. L., R. L. Strawderman, Y. H. Schukken, S. J. Wells, A. K. Pradhan, L. A. Espejo, R. H. Whitlock, J. S. Van Kessel, J. M. Smith, D. R. Wolfgang, and Y. T. Gröhn. 2010. Effect of Johne's disease status on reproduction and culling in dairy cattle. J. Dairy Sci. 93:3513-3524. https://doi.org/10.3168/jds.2009-2742.

Sweeney, R. W., I. A. Gardner, M. E. I. Hines, R. Anderson, T. M. Byrem, M. T. Collins, and R. H. Whitlock. 2014. Comparison of
3 fecal culture, 2 fecal PCR, 2 serum ELISA, and milk ELISA for diagnosis of paratuberculosis in US dairy cattle. In 12th International Colloquium on Paratuberculosis. Parma, Italy. International Association for Paratuberculosis, Parma, Italy.

Sweeney, R. W., R. H. Whitlock, S. McAdams, and T. Fyock. 2006. Longitudinal study of ELISA seroreactivity to Mycobacterium avium ssp. paratuberculosis in infected cattle and culture-negative herd mates. J. Vet. Diagn. Invest. 18:2-6. https://doi.org/10.1177/ 104063870601800102.

Sweeney, R. W., R. H. Whitlock, and A. E. Rosenberger. 1992. Mycobacterium paratuberculosis isolated from fetuses of infected cows not manifesting signs of the disease. Am. J. Vet. Res. 53:477-480.

USDA ERS (Economic Research Service). 2015. National Milk Cost of Production, 2015. Accessed Feb. 4, 2017. https://www.ers.usda .gov/data-products/milk-cost-of-production-estimates.aspx.

USDA NASS (National Agricultural Statistics Service). 2015. Agricultural Prices. Accessed Apr. 14, 2017. http://usda.mannlib.cornell .edu/usda/nass/AgriPric//2010s/2015/AgriPric-03-30-2015.pdf.

USDA NASS (National Agricultural Statistics Service). 2017. Agricultural Prices. Accessed Apr. 14, 2017. http://usda.mannlib.cornell .edu/usda/nass/AgriPric//2010s/2017/AgriPric-03-30-2017.pdf.

van Roermund, H. J. W., D. Bakker, P. T. J. Willemsen, and M. C. M. de Jong. 2007. Horizontal transmission of Mycobacterium avium ssp. paratuberculosis in cattle in an experimental setting: Calves can transmit the infection to other calves. Vet. Microbiol 122:270-279. https://doi.org/10.1016/j.vetmic.2007.01.016.

van Schaik, G., Y. H. Schukken, C. Crainiceanu, J. Muskens, and J. A. VanLeeuwen. 2003. Prevalence estimates for paratuberculosis adjusted for test variability using Bayesian analysis. Prev. Vet. Med. 60:281-295. https://doi.org/10.1016/S0167-5877(03)00157-0.

van Schaik, G., S. M. Stehman, R. H. Jacobson, Y. H. Schukken, S. J. Shin, and D. H. Lein. 2005. Cow-level evaluation of a kinetics ELISA with multiple cutoff values to detect fecal shedding of $M y$ cobacterium avium subspecies paratuberculosis in New York State dairy cows. Prev. Vet. Med. 72:221-236. https://doi.org/10.1016/ j.prevetmed.2005.01.019.

Vitale, N., R. Possidente, V. D'Errico, A. Dondo, S. Bergagna, R. Barbero. and L. Chiavacci, 2014. Estimating diagnostic accuracy of paratuberculosis (PTB) diagnostic test with latent class models. In 12th International Colloquium on Paratuberculosis. Parma, Italy. International Association for Paratuberculosis, Parma, Italy.

Whitlock, R., S. Wells, R. Sweeney, and J. Van Tiem. 2000. ELISA and fecal culture for paratuberculosis (Johne's disease): Sensitivity and specificity of each method. Vet. Microbiol. 77:387-398. https://doi.org/10.1016/S0378-1135(00)00324-2. 